\title{
Effect of Ripening Stage on Astringency Removal of 'Rama Forte' Persimmon
}

\author{
F.K. Edagi, I. Sestari, F.A.M. Terra, \\ D.G. Chiou and R.A. Kluge \\ Department of Biological Science \\ 'Luiz de Queiroz' Agricultural College \\ University of São Paulo \\ C.P. 9, 13418-900, Piracicaba, SP \\ Brazil
}

\author{
L.R. Antoniolli \\ Embrapa Uva e Vinho \\ Bento Gonçalves, RS \\ Brazil
}

Keywords: Diospyros kaki, carbon dioxide, exposure time, flesh firmness, storage

\begin{abstract}
Ripening stage is one of the most important factors that influence astringency removal from persimmon fruit. This work aimed to evaluate the efficiency of tannin polymerization for fruit harvested at different ripening stages and its influence on quality parameters. Fruit at three ripening stages (yellow, orange and red) were exposed to $70 \mathrm{kPa} \mathrm{CO}$ during 12 and $18 \mathrm{~h}$, at $22^{\circ} \mathrm{C}$ and $95 \% \mathrm{RH}$. The soluble tannin content decreased abruptly two days after $\mathrm{CO}_{2}$ treatment, regardless of ripening stage and exposure time. Yellow fruit exposed for $18 \mathrm{~h}$ were completely nonastringent one day after treatment. In general, with the advance in ripening and increase in exposure time, fruit firmness decreased. Astringency removal with $\mathrm{CO}_{2}$ promoted an immediate increase in respiration rate, significantly higher for red fruit. The stress caused by high $\mathrm{CO}_{2}$ induced a significant increase in ethylene synthesis after two days at $22^{\circ} \mathrm{C}$. In yellow fruit, the exposition to $70 \mathrm{kPa} \mathrm{CO}_{2}$ for 18h, maintains firmness during 16 days and completely removes the astringency after two days.
\end{abstract}

\section{INTRODUCTION}

The 'Rama Forte' persimmon belongs to the variable group, which present astringency and clear flesh when paternocarpic development of the fruit occurs, and dark flesh, non astringent on the presence of seeds (Campo-Dall'Orto et al., 1996). This fact implies the necessity of a postharvest treatment to remove the astringency before fruit commercialization. One of the methods used to remove astringency in persimmons utilizes atmospheres with high carbon dioxide concentrations or atmospheres with low oxygen concentrations (Arnal and Del Rio, 2003; Salvador et al., 2005). The effectiveness of these methods occurs due to the fact that it promotes anaerobic respiration of the fruit, which accumulates acetaldehyde. This accumulated compound reacts with soluble tannins (responsible for the astringency) making these tannins become insoluble or polymerized (Matsuo and Itoo, 1982; Oshida et al., 1996; Taira et al., 1997; Salvador et al., 2007).

Persimmon fruits at different ripening stages have a different response in relation to firmness maintenance, when submitted to astringency removal treatments and following storage (Salvador et al., 2005). The fruits at a more advanced ripening stage tend to have a rapid softening during storage, while fruits at an earlier ripening stage lose firmness in a slower way, probably due to the lesser respiration rates and in ethylene production.

The objective of this work was to evaluate the influence of ripening stages of 'Rama Forte' persimmon fruit, on efficiency of the astringency removal process and its influence on maintenance of fruit quality stored at room temperature.

\section{MATERIALS AND METHODS}

Persimmons of cultivar 'Rama Forte' were harvested at different ripening stages (yellow, orange and red) and transported to the Postharvest Physiology Laboratory at the University of Sao Paulo in Piracicaba. Fruit were selected according to ripening stage, 
uniformity on weight and shape, and damaged and blemished fruit was removed. Fruit of each treatment was placed into cardboard boxes and afterwards into chambers where the astringency removal process was applied under a $70 \% \mathrm{CO}_{2}$ atmosphere for 12 and $18 \mathrm{~h}$.

After the astringency removal process the fruit were stored at room temperature $\left(22 \pm 1{ }^{\circ} \mathrm{C}\right.$ and $\left.90 \% \mathrm{RH}\right)$ and were evaluated by the following parameters: flesh firmness, astringency index and soluble tannins content. The evaluations were made at harvest, immediately after $\mathrm{CO}_{2}$ treatment (-1 day), and following intervals of two days for a period of 16 days of shelf life. Flesh firmness was measured with a digital penetrometer; measurements were performed on two opposite sides of each individual fruit after peel removal, with an $8 \mathrm{~mm}$ diameter tip. The degree of soluble tannins was estimated visually by evaluating color development during the reaction between tannin with ferric chloride. Persimmons were cut equatorially, and immediately the freshly cut surface was printed in a paper filter previously treated with a $5 \% \mathrm{FeCl}_{3}$ solution as proposed by Gazit and Levy (1963). The printed paper was scored visually on a scale from 5 (extremely astringent) to 1 (not astringent). The soluble tannins content was determined spectrophotometrically utilizing Folin-Ciocalteu reagent, according to the method described by Taira (1996).

Respiration rate and ethylene production were also evaluated. Fruit were put in glass hermetic recipients for two hours and maintained at $22 \pm 1{ }^{\circ} \mathrm{C}$ and $90 \% \mathrm{RH}$. The measurements were taken daily, during 11 days, using a gas chromatograph equipped with a FID detector.

The experimental design was entirely random, at the factorial schedule $6 \times 12$. The study's factors were: treatments, in 6 levels, and storage periods in 12 levels (before treatment, after treatment and in the 16 following days). Four repetitions were used, each one of them with three fruits. The results were submitted to standard deviation error analysis.

\section{RESULTS AND DISCUSSION}

\section{Flesh Firmness}

The yellow persimmons presented an initial flesh firmness of $53.7 \mathrm{~N}$, while the orange and red persimmons presented 33.5 and $36.7 \mathrm{~N}$ of flesh firmness respectively (Fig. 1). After the application of astringency removal treatments reduction in fruit flesh firmness was observed, regardless of $\mathrm{CO}_{2}$ exposure time. Red fruit exposed to $\mathrm{CO}_{2}$ during $18 \mathrm{~h}$ had a decrease of firmness values near of $4.8 \mathrm{~N}$, which limited shelf life of these fruit to eight days at a temperature of $22 \pm 1^{\circ} \mathrm{C}$ (Fig. 1), while fruit of other treatments did not present such a sharp decrease in flesh firmness, maintaining values above the minimal level for commercialization $(10 \mathrm{~N})$ until the end of storage.

It is well know that $\mathrm{CO}_{2}$ has beneficial effects on maintenance of fruit quality. However, a high concentration can contribute to physiological disorders such as flesh softening (Pesis and Ben-Arie, 1984). This fact, combined with the advanced ripening stage of these persimmons, might explain flesh softening behavior presented by red fruit exposed to $\mathrm{CO}_{2}$ for $18 \mathrm{~h}$.

The formation of three distinct groups was also verified. One group formed by yellow fruit, that regardless of exposure time to $\mathrm{CO}_{2}$, presented higher flesh firmness, was followed by a group of red fruit treated for $12 \mathrm{~h}$ and orange fruit exposed to $\mathrm{CO}_{2}$ for 12 and $18 \mathrm{~h}$, that presented median firmness values, and finally by a group of red fruit treated for $18 \mathrm{~h}$, that presented the lowest flesh firmness values.

\section{Astringency Index}

In relation to the astringency index, it was verified that all the fruit, regardless of the treatment submitted by those, presented index 5 at initial evaluation. At the final of treatments red fruit exposed to $\mathrm{CO}_{2}$ for $12 \mathrm{~h}$ were still very astringent (3.8 index), while other fruit presented slight astringency to astringency (Fig. 2).

It was observed that on the first day of storage, yellow fruit treated for 12 and $18 \mathrm{~h}$ were already slightly astringent to non astringent, 1.75 and 1.0 index, respectively, while 
other fruit were still astringent. On the second storage day only orange and red fruit treated for $12 \mathrm{~h}$ showed astringency, indicating that for these ripening stages a longer exposure to $\mathrm{CO}_{2}$ is recommended to obtain a better astringency removal. After the second storage day fruit of all treatments have variability between slight astringency and non astringency with the exception of orange fruit treated for $12 \mathrm{~h}$ that were medially astringent until the $14^{\text {th }}$ day of storage.

Orange fruit exposed to $\mathrm{CO}_{2}$ for 12 and $18 \mathrm{~h}$ presented astringency recurrence on the $8^{\text {th }}$ and $10^{\text {th }}$ storage day, respectively. This might have occurred due to the fact that the process of astringency removal on these fruit was not complete, hence promoting tannin resolubilization, a phenomenon reported previously on 'Triumph' (Ben-Arie and Sonego, 1993) and 'Rama Forte' persimmon (Edagi et al., 2006). This process is called astringency resurgence.

\section{Tannins Soluble Content}

It was observed after the end of astringency removal process that yellow fruit exposed to $\mathrm{CO}_{2}$ for 12 and $18 \mathrm{~h}$ presented 4.9 and $3.2 \mu \mathrm{g}$ of gallic acid (Fig. 3), respectively, being significantly different from the orange and red fruit treated with $\mathrm{CO}_{2}$ for $12 \mathrm{~h}$ (14 and $19.9 \mu \mathrm{g}$ of gallic acid, respectively). These results, when compared to those from the astringency index, strengthen the efficiency obtained by the astringency removal treatments for the fruit at the yellow ripening stage.

All persimmon fruit have a decrease in the soluble tannins content during the storage period. This decline in soluble tannin as storage time elapsed may well result from accelerated condensation reactions, possibly between the tannin and accumulated acetaldehyde (Matsuo and Itoo, 1982).

Thereafter 8 and 10 days of shelf life, the orange fruit exposed to $\mathrm{CO}_{2}$ during 12 and $18 \mathrm{~h}$, presented an increase in soluble tannins values. This enhancement corroborates with the highest astringency index observed and indicates once again the event of the astringency resurgence process (Figs. 2 and 3).

\section{Respiration Rates and Ethylene Production}

As showed in Figure 4, one day after treatments, two distinct groups as regards the respiratory activity were observed. Fruit exposed to $\mathrm{CO}_{2}$ during $18 \mathrm{~h}$, regardless of ripening stage, presented greater respiration rates $\left(30.9-32.4 \mathrm{ml} \mathrm{CO}_{2} \mathrm{~kg}^{-1} \mathrm{~h}^{-1}\right)$, followed by the fruit treated for $12 \mathrm{~h}\left(18.7-24.1 \mathrm{ml} \mathrm{CO}_{2} \mathrm{~kg}^{-1} \mathrm{~h}^{-1}\right)$ (Fig. 4). After $48 \mathrm{~h}$, a reduction in fruit respiratory activity was found, with the maintenance of initial behavior, except for the red fruit treated during 12 and $18 \mathrm{~h}$, because these fruit presented respiration rates significantly higher than yellow and orange fruits treated during the same period of time.

Persimmon fruits normally produce small amounts of ethylene (Kader, 1992). Nevertheless, they are very sensitive to ethylene action, and exposure to low concentrations of ethylene accelerates ripening. An increase in ethylene production was observed after $48 \mathrm{~h}$. in orange fruit exposed to $\mathrm{CO}_{2}$ during $18 \mathrm{~h}$ and in the red fruit exposed to $\mathrm{CO}_{2}$ during $12 \mathrm{~h}$ (Fig. 4), while the red fruit treated during $18 \mathrm{~h}$ presented an ethylene peak production after $72 \mathrm{~h}$ of $\mathrm{CO}_{2}$ treatment. An ethylene peak of production was also observed but with smaller intensity on the other treatments and for some of those treatments this peak occurs only $96 \mathrm{~h}$ after the astringency removal process. Itamura et al. (1997) also reported enhancement on ethylene production in 'Saijo' persimmon treated with $\mathrm{CO}_{2}$ to remove astringency.

It is possible to notice, therefore, that astringency removal with $\mathrm{CO}_{2}$ promotes immediate increase in fruit respiration rates, while an ethylene peak production is verified only after 48, 72 or $96 \mathrm{~h}$, besides that, the stress caused by exposure to high $\mathrm{CO}_{2}$ concentrations appears to be greater in fruit that have an advanced ripening stage, being responsible for the maintenance of respiration rates in higher levels and for greater ethylene syntheses, with inherent consequences to ripening and senescence process. 


\section{CONCLUSIONS}

The yellow fruit, regardless of exposure time to $\mathrm{CO}_{2}$, had higher flesh firmness, differing of others treatments.

Orange fruit, regardless of exposure time to $\mathrm{CO}_{2}$, presented astringency recurrence and remained slightly astringent during the entire storage period.

Persimmon fruit in an advanced ripening stage submitted to astringency removal treatments suffer a greater stress due to this process and during the storage period it has higher respiration rates and a greater ethylene peak production, what implies in rapid fruit softening.

In a general way, it is recommended that the astringency removal process in 'Rama Forte' persimmons, at the yellow ripening stage, be conducted with exposure of the fruit to $70 \% \mathrm{CO}_{2}$ atmosphere during 12 or $18 \mathrm{~h}$, which will result in slightly or non astringent fruit from the first day and in a suitable flesh firmness during 16 days under $22^{\circ} \mathrm{C}$ with $90 \% \mathrm{RH}$.

\section{ACKNOWLEDGEMENTS}

This work was supported by Fundação de Amparo à Pesquisa do Estado de São Paulo (FAPESP).

\section{Literature Cited}

Arnal, L. and Del Río, M.A. 2003. Removing astringency by carbon dioxide and nitrogen enriched atmospheres in persimmon fruit cv. Rojo Brillante. J. Food Sci. 68:15161518.

Ben-Arie, R. and Sonego, L. 1993. Temperature affects astringency removal and recurrence in persimmon. J. Food Sci. 58:1397-1400.

Campo-Dall'orto, F.A., Ojima, M., Barbosa, W. and Zullo, M.A.T. 1996. Novo processo de avaliação da adstringência dos frutos no melhoramento do caquizeiro. Brangatia, 55:237-243.

Edagi, F.K., Terra, F.A.M., Miguel, P. and Kluge, R.A. 2006. Recorrência de adstringência em frutos de caqui cv. Rama-Forte destanizados com dióxido de carbono. Anais do Simpósio Internacional de Iniciação Científica da Universidade de São Paulo.

Itamura, H., Ohno, Y. and Yamamura, H. 1997. Characteristics of fruit softening in Japanese persimmon 'Saijo'. Acta Hort. 436:179-188.

Kader, A.A. 1992. Postharvest Technology of Horticultural Crops. Division of Agriculture and Natural Resources. Oakland, California.

Matsuo, T. and Itoo, S. 1982. A model experiment for de-astringency of persimmon fruit with high carbon dioxide treatment: in vitro gelation of kaki-tannin by reacting with acetaldehyde. J. Agr. Biol. Chem. 46:683-689.

Oshida, M., Yonemori, K. and Sugiura, A. 1996. On the nature of coagulated tannins in astringency-type persimmon fruit after an artificial treatment of astringency removal. Postharvest Biol. Tech. 8:317-327.

Pesis, E. and Ben-Arie, R. 1984. Involvement of acetaldehyde and ethanol accumulation during induced deastringency of persimmon fruits. J. Food Sci. 49:896-899.

Salvador, A., Arnal, L., Monterde, A. and Martínez-Jávega, J.M. 2005. Influence of ripening stage at harvest on chilling injury symptoms of persimmon cv. 'Rojo Brillante' stored at different temperatures. Food Sci. Tech. Int., 11:359-365.

Salvador, A., Arnal, L., Besada, C.; Larrea, V., Quiles A. and Pérez-Munuera, I. 2007. Physiological and structural changes during ripening and deastringency treatment of persimmon fruit cv. 'Rojo Brillante'. Postharvest Biol. Tech. 46:181-188.

Taira, S. 1996. Adstringency in Persimmon. p.97-110. In: H.F. Linskens and J.F. Jackson (eds.), Modern Methods of Plant Analysis, v.18. Berlin.

Taira, S., Ono, M. and Matsumoto, N. 1997. Reduction of persimmon astringency by complex formation between pectin and tannins. Postharvest Biol. Tech.12:265-271. 


\section{Figures}

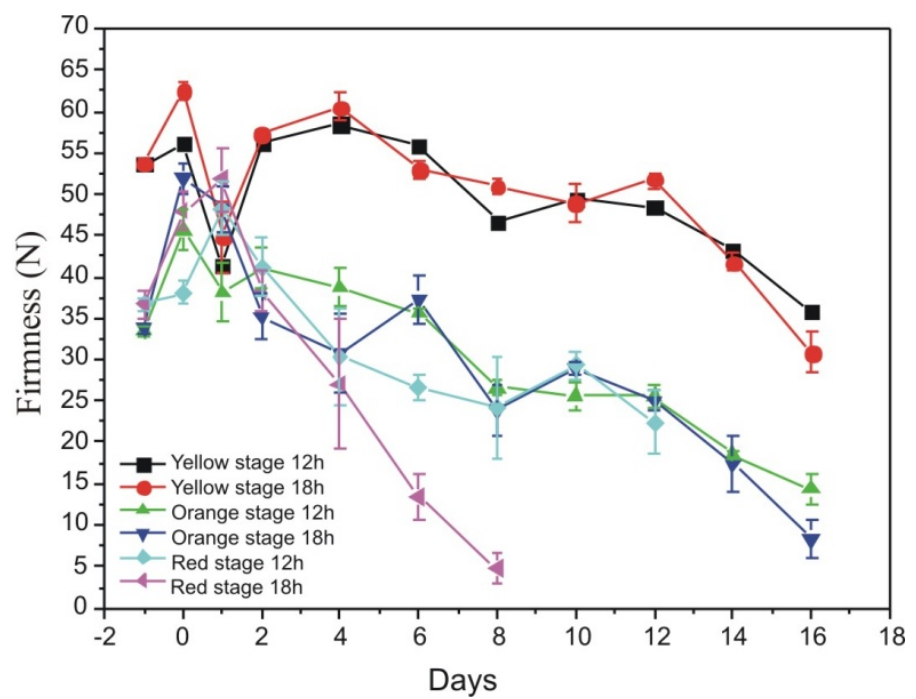

Fig. 1. Flesh firmness of 'Rama Forte' persimmon fruit stored during 16 days under $22 \pm$ $1{ }^{\circ} \mathrm{C}$ and $90 \%$ RH. (-1 day = before astringency removal).

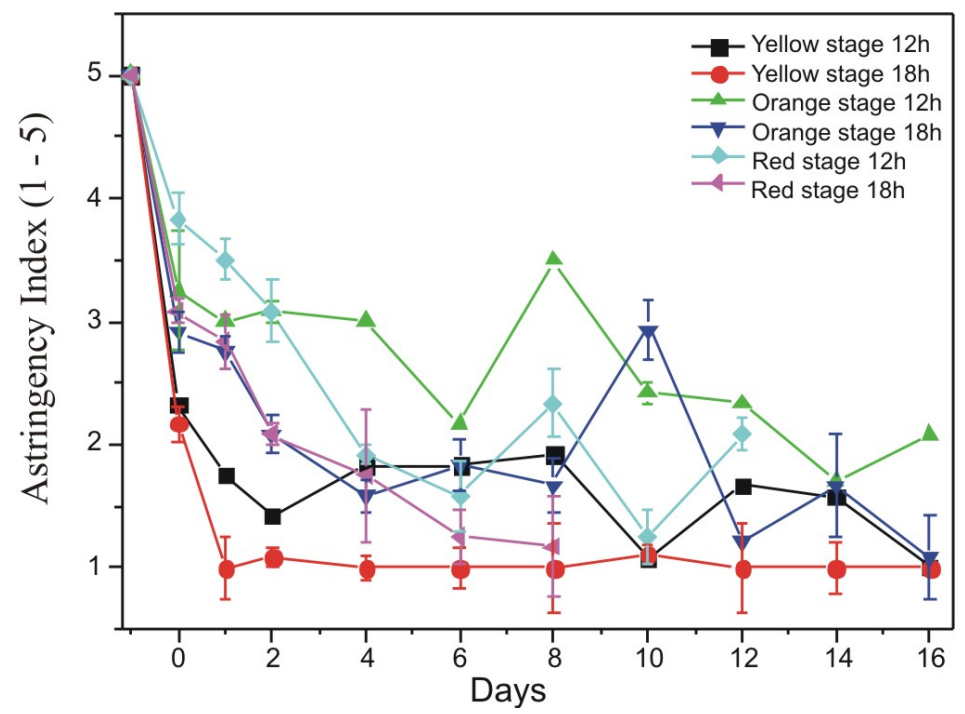

Fig. 2. Astringency index (5 to 1 ) of 'Rama Forte' persimmon fruit stored during 16 days under $22 \pm 1{ }^{\circ} \mathrm{C}$ and $90 \% \mathrm{RH}$. The grades correspond to: 5=very astringent; $4=$ astringent; $3=$ medium astringent; $2=$ slightly astringent; $1=$ non astringent $(-1$ day $=$ before astringency removal). 


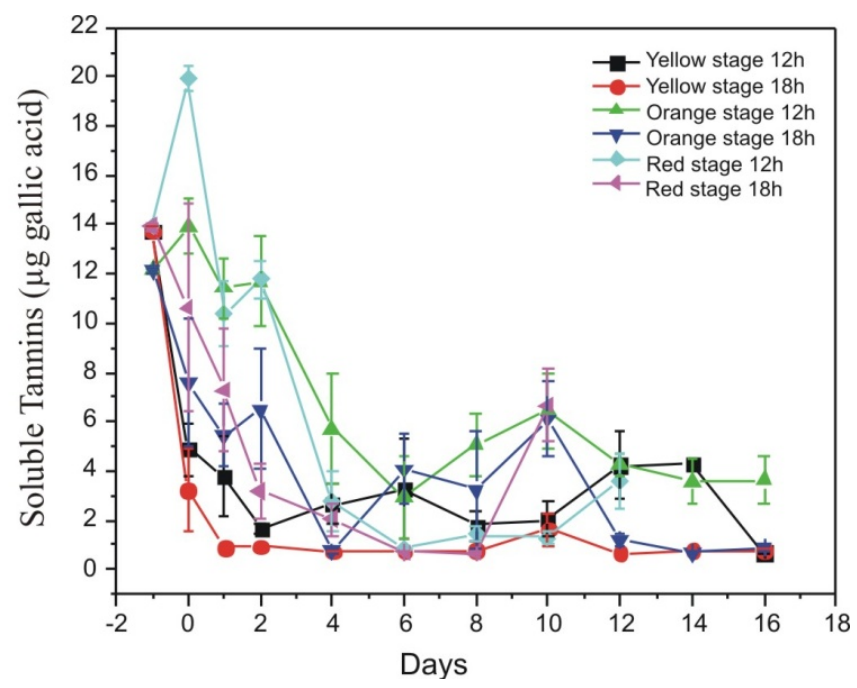

Fig. 3. Soluble tannins content ( $\mu \mathrm{g}$ of gallic acid) of 'Rama Forte' persimmon fruit stored during 16 days under $22 \pm 1^{\circ} \mathrm{C}$ and $90 \% \mathrm{RH}$. (-1 day = before astringency removal).
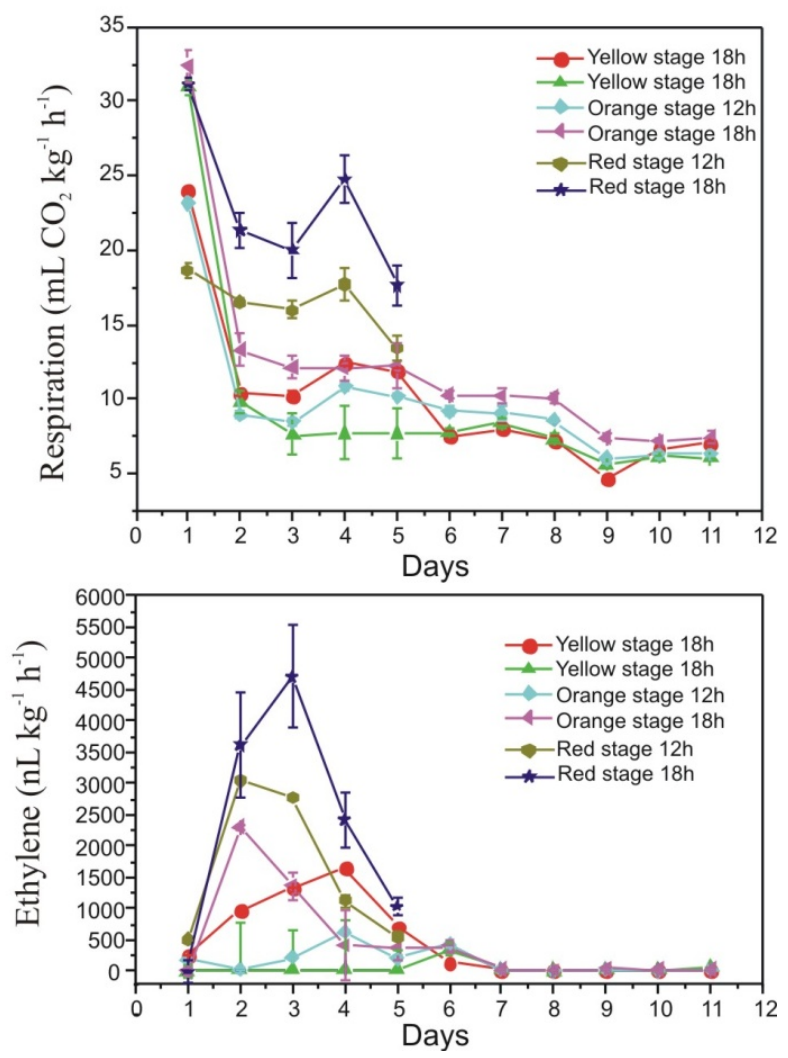

Fig. 4. Respiration rate $\left(\mathrm{ml} \mathrm{CO} \mathrm{Cg}^{-1} \mathrm{~h}^{-1}\right)$ and ethylene synthesis $\left(\mathrm{nl} \mathrm{C}_{2} \mathrm{H}_{4} \mathrm{~kg}^{-1} \mathrm{~h}^{-1}\right)$ of 'Rama Forte' persimmon fruit stored during 16 days under $22 \pm 1^{\circ} \mathrm{C}$ and $90 \% \mathrm{RH}$. $(-1$ day $=$ before astringency removal). 